\title{
Salmonella enterica serovar Typhimurium sseK3 induce cell apoptosis and enhance glycolysis in macrophages
}

\section{Fuyu Du}

Henan University of Science and Technology

\section{Chuan Yu}

Henan University of Science and Technology

Chunjie Zhang ( $\nabla$ cjzhang@sina.com )

https://orcid.org/0000-0002-4079-8091

\section{Yinju Li}

Henan University of Science and Technology

\section{Chengshui Liao}

Henan University of Science and Technology

Lei He

Henan University of Science and Technology

\section{Xiangchao Cheng}

Henan University of Science and Technology

\section{Xiaojie Zhang}

Henan University of Science and Technology

\section{Research article}

Keywords: S. Typhimurium, sseK3, macrophages apoptosis, glycolysis

Posted Date: November 14th, 2019

DOI: https://doi.org/10.21203/rs.2.17312/v1

License: (1) (1) This work is licensed under a Creative Commons Attribution 4.0 International License. Read Full License

Version of Record: A version of this preprint was published at BMC Microbiology on June 9th, 2020. See the published version at https://doi.org/10.1186/s12866-020-01838-z. 


\section{Abstract}

Background: Salmonella enterica serovar Typhimurium (S. Typhimurium) is an important infectious disease pathogen. Previous studies have identified that S. Typhimurium secreted effector K3 (SseK3) is a novel translated and secreted protein, but it is unclear whether this protein exerts a significant role in the progress of apoptosis and glycolysis in macrophages. Results: The S. Typhimurium SL1344 wild-type (WT) group, $\Delta$ sseK3 mutant group and sseK3-complemented group were used to infect macrophages and the effects of sseK3 on apoptosis and glycolysis of macrophages were investigated. The adherence and invasion of $\Delta$ sseK3 mutant group for macrophages were similar to WT group and sseK3-complemented group, indicating that SseK3 did not play an important role in the adherence and invasion of S. Typhimurium for macrophages. However, the apoptosis percentage of the $\Delta$ sseK3 mutant group was much lower than WT group and sseK3-complemented group using flow cytometry. The caspase-3, caspase-8 and caspase- 9 enzyme activity of the $\Delta$ sseK3 mutant group were decreased significantly compared with WT group and sseK3-complemented group, which suggested that sseK3 could improve the activities of caspase- 3 , caspase- 8 and caspase- 9 enzyme. We also found that the pyruvic acid level did not significantly change among $\Delta$ sseK3 mutant group, WT group and sseK3-complemented group, but the lactic acid level of $\Delta$ sseK3 mutant group was much lower than WT group and sseK3complemented group. The ATP level of $\Delta$ sseK3 mutant group was remarkably higher than WT group and sseK3-complemented group. These indicated that the sseK3 enhanced the level of glycolysis of macrophages infected by S. Typhimurium. Conclusions: Our data showed that the sseK3 of S. Typhimurium can promote macrophages apoptosis and influence glycolysis levels of macrophages. These results may give a better clue about the relationship between apoptosis and glycolysis in macrophages induced by S. Typhimurium sseK3. Keywords: S. Typhimurium, sseK3, macrophages apoptosis, glycolysis

\section{Background}

Salmonella enterica serovar Typhimurium ( $S$. Typhimurium) is one of the most significant zoonotic pathogens that pose a threat to humans [1]. After being contaminated by Salmonella, animal products can be transmitted to humans through the food chain, threatening human health, and potentially leading to deaths $[1,2]$. Besides, $S$. Typhimurium can survive and replicate in macrophages. The macrophages or dendritic cells were reported to be able to carry bacteria from the Peyer's patches to adjacent lymph nodes, spleen and liver in mouse models [3].

One of the most essential metabolic pathways in cells is glycolysis [4]. Under anaerobic condition, the pyruvate is eventually converted into lactic acid. However, under aerobic conditions, pyruvic acid enters the tricarboxylic acid cycle (TCA cycle) and eventually is oxidized to $\mathrm{CO}_{2}$ and $\mathrm{H}_{2} \mathrm{O}$ [5]. Liu found that Resveratrol reduced the production of lactic acid to inhibit glycolysis and induce cell apoptosis [6]. Kok found that Sirtuin 6 reduced the production of HK2 during glycolysis, thereby regulating apoptosis induced by hypoxia [7]. Hypoxia inducible factor-1a (HIF-1a) could inhibit the production of Adenosine triphosphate (ATP) and thus inhibit the glycolysis of mouse granulosa cells [8]. Moreover, studies have 
shown that $S$. Typhimurium can induce cell apoptosis $[9,10]$. There is increasing evidence in recent years that the apoptosis is closely related to glycolysis activities [11-13]. Therefore, the glycolysis is closely related to cell apoptosis.

The immune cells were able to detect the metabolic abnormalities caused by Salmonella with the help of inflammatory signals, and glycolysis was essential in $S$. Typhimurium infection with macrophages [14, 15]. Following invasion or phagocytic uptake into the host cell, one of the key virulence determinants is the Salmonella pathogenicity island 2 (SPI-2)-encoded type III secretion system 2 (T3SS2), which delivers 28 effector proteins into the host cell [16-18]. Previous studies have identified that Salmonella secreted effector K3 (SseK3) is a novel translated and secreted protein of $S$. Typhimurium, which is encoded by sseK3 gene [19]. SseK3 was a glycosyltransferase, which could transfer an $\mathrm{N}$-acetyl-glucosamine moiety onto the guanidino group of a target arginine, regulating host cell function. The protein belongs to the glycosyltransferase type-A family of glycosyltransferase enzymes and binds the ligand in a metal iondependent manner via a DXD motif [20]. SseK3 was co-regulated with the T3SS2 inside host cells and was injected into infected host cells. [21]. However, the mechanism of activity of SseK3 during $S$. Typhimurium infection was completely unclear, especially there is no research about $s s e K 3$ affecting macrophages apoptosis and glycolysis.

In this study, we determined that sseK3 from $S$. Typhimurium induced macrophages death and glycolysis. Our data showed that the sseK3 of $S$. Typhimurium could promote macrophage apoptosis and improve glycolysis levels. These results would supply a critical step to provide a better understanding of the relationship between glycolysis and apoptosis in $S$. Typhimurium-infected macrophages.

\section{Results}

\section{Analysis of adherence and invasion}

Adherence and invasion to RAW264.7 cells of the host could ensure the same level of infecting cells at the post experiments. Compared to WT, the $\Delta s s e K 3$ mutant exhibited similar adhesion to and invasion of RAW264.7 cells. However, the sseK3-complemented strain regained the adherence and invasion ability of WT (Fig.1). This result suggests that sseK3 does not play an important role in the adherence and invasion of RAW264.7 cells by S. Typhimurium. Moreover, the WT, the $\Delta$ sseK3 mutant and sseK3-complemented strains have the similar level of infecting RAW264.7 cells.

\section{Analysis of cell apoptosis}

The apoptosis assay was performed as previously described [22, 23]. Apoptosis assay showed that the apoptosis percent of $\Delta s s e K 3$ mutant group was much lower than that of the WT and sseK3complemented groups. In the $\Delta$ sseK3 mutant group, the FITC-Annexin $\mathrm{V}$ positive cells were $3.78 \%$, while in the WT group, it was $14.64 \%$ (Fig.2), suggesting that SseK3 encoded by sseK3 plays an important role in the process of inducing macrophages apoptosis by $S$. Typhimurium. 


\section{Analysis of caspase activity}

In the process of apoptosis, the caspase played an essential role [24]. Caspase-3, 8, 9 activities were measured at different time points respectively (Fig.3). The caspase-3, caspase-8 and caspase-9 activities of mock group was much lower than infection groups ( $\Delta$ sseK3 mutant, WT and sseK3-complemented groups), which indicated that the infection groups could stimulate the activities of caspase-3,8,9 in macrophages. However, it could be seen from Fig. 3 that the caspase- 8 and caspase-9 activities of $\triangle$ sseK3 mutant group significantly lower than WT group and sseK3-complemented group at $2 \mathrm{~h}, 4 \mathrm{~h}, 6 \mathrm{~h}$ and $8 \mathrm{~h}(* \star * P<0.001)$, suggesting that SseK3 could induce the activation of caspase-8 and caspase- 9 . As for caspase-3, there were no significant difference among $\Delta s s e K 3$ mutant group ( $P>0.05)$, WT group and sseK3-complemented group at $2 \mathrm{~h}$. But significant difference among infection groups was observed at 4 $\mathrm{h}, 6 \mathrm{~h}$ and $8 \mathrm{~h}(\star \star \star P<0.001)$, the caspase-3 activity of $\Delta s s e K 3$ mutant group significantly lower than WT group and sseK3-complemented group. These results illustrated that SseK3 served a pivotal role in the process of inducing macrophage apoptosis by $S$. Typhimurium.

\section{Analysis of glycolysis}

The analysis of glycolysis was performed as previously described [25-27]. To determine the SseK3 whether can affect the glycolysis of macrophages infected by $S$. Typhimurium, the level of pyruvic acid, lactic acid and ATP were detected respectively (Fig.4). The results showed that the level of pyruvic acid was no significant difference at $2 \mathrm{~h}, 4 \mathrm{~h}, 6 \mathrm{~h}$ and $8 \mathrm{~h}(P>0.05)$ among each group. However, as for lactic acid, there was significant difference between mock group and infection group at $2 \mathrm{~h}, 4 \mathrm{~h}, 6 \mathrm{~h}$ and $8 \mathrm{~h}$ ( $* * *<0.001)$. The glycolysis of macrophages of infection group were remarkably increased compared with mock group, and the lactic acid level of $\triangle s s e K 3$ mutant group was significantly lower than WT and sseK3-complemented groups at $4 \mathrm{~h}, 6 \mathrm{~h}$ and $8 \mathrm{~h}(* \star * P<0.001)$. The investigations of glycolysis in macrophages suggested SseK3 encoded by sseK3 could boost the lactic acid of macrophages. We also found that the level of ATP in infection groups were significantly lower than in mock group at $4 \mathrm{~h}, 6 \mathrm{~h}$ and $8 \mathrm{~h}(* \star * P<0.001)$, and the level of ATP in the $\triangle s s e K 3$ mutant group was much higher than in WT and sseK3-complemented groups at $4 \mathrm{~h}, 6 \mathrm{~h}$ and $8 \mathrm{~h}(* \star \star P<0.001)$. These results illustrated that SseK3 encoded by sseK3 could improve the glycolysis of macrophages through lactic acid and the ATP level changing.

\section{Discussion}

Many secreted proteins of Salmonella exert different virulence functions in the process of survival and replication in cells [28]. T3SS2 helps Salmonella transport virulence (effector) proteins in SCVs into host cells [29]. S. Typhimurium possesses the SseK family of proteins, including SseK1, SseK2 and SseK3, which are T3SS effectors [1,30]. SseK3 is an important protein during Salmonella infection of cells and plays a pivotal role in the natural host immune process $[19,21]$. Multiple secretory proteins of $S$. Typhimurium exerted enormous stress during the period of apoptosis of cells and related to cell apoptosis $[28,29,31,32]$. Nonetheless, the role of SseK3 in the process of cells apoptosis and glycolysis 
is unclear. This research is the first to show that SseK3 encoded by sseK3 of $S$. Typhimurium could improve cell apoptosis and boost glycolysis in macrophage.

Santo found that early sipB-dependent and delayed sipB-independent mechanisms could cause the apoptosis induced by $S$. Typhimurium [33]. Kasinskas investigated that the lacking ribose chemoreceptors of $S$. Typhimurium localized in tumor quiescence and induced apoptosis [34]. Besides, there had shown that the CAMP receptor protein of $S$. Typhimurium could induce the apopotosis of macrophages [35]. Therefore, in order to determine the relationship between $S$. Typhimurium sseK3 and macrophages apoptosis, we used the WT, $\Delta$ sseK3 mutant and sseK3-complemented strains to infect the macrophages. In our study, we found that the adherence percentage and invasion percentage of $\Delta s s e K 3$ mutant group were similar to WT group and sseK3-complemented group during the infecting period ( $P>0.05$ ), which ensured that the WT, $\Delta$ sseK3 mutant and sseK3-complemented strains had the same level going through into the macrophages. Subsequently, the apoptosis in different infection groups were detected by the assay of flow cytometry. The results showed that the apoptosis percentage of $\Delta s s e K 3$ mutant group (3.78\%) was much lower than WT group (14.64\%) and sseK3-complemented group (11.81\%). These indicated that deletion of the sseK3 gene significantly affected the cell apoptosis.

The caspases activities were further to be detected. The activation of caspases exerts essential role on the cells apoptosis induced by the loss of mitochondria membrane [36]. There had shown that the SopB of Salmonella could protect host cell from apoptosis induced by caspase-3 [37]. The activation of caspase- 3 and caspase- 9 showed that the apoptosis was activated in the macrophages infected by Escherichia coli bacteria [38]. Besides, the caspase-8 influenced the synthesis of pro-IL-1 $\beta$ and was essential for the apoptosis of cells induced by Salmonella [39]. As these previously researches, we investigated the caspase-3, caspase-8 and caspase-9 activity during the apoptosis of macrophages infected by $S$. Typhimurium. We found that caspase -3 , caspase- 8 and caspase- 9 activity were remarkably increased in infection groups compared with mock group at $2 \mathrm{~h}, 4 \mathrm{~h}, 6 \mathrm{~h}$ and $8 \mathrm{~h}$ ( $* \star * P<0.001$ ), indicating that the apoptosis were activated in the macrophages apoptosis. Furthermore, the activity of caspase-3, caspase-8 and caspase-9 in $\Delta$ sseK3 mutant group were much lower than in WT group and sseK3complemented group, which suggested that SseK3 may be a pivotal component for $S$. Typhimurium activating apoptosis in macrophages.

There were increasing evidences that the apoptosis and glycolysis had closely relationship. Previously, Comin-Anduix found that fermented wheat germ extract (FWGE) inhibited the glycolysis and induced the apoptosis of tumor cells [40]. Jeong found that the modification of glycolysis could change the sensitivity of apoptosis through mitochondria pathway [41]. Recently, There has shown that the glycolysis could be inhibited and the cell death was further blocked [42]. Li found that methyl jasmonate could inhibit the glycolysis and induce apoptosis of tumor cells [43]. Sumi found that propofol could improve glycolysis of cells and lead to the apoptosis of cells [44]. The pyruvic acid, lactic acid and ATP were important components in the process of cell glycolysis. There have various metabolic pathway to produce pyruvic acid [45]. Pyruvic acid could enter the TCA cycle to be completely oxidized in aerobic condition, whereas it could become lactic acid under anaerobic oxygen condition [46, 47]. HIF-1a could 
prohibit the production of ATP and thus regulate the glycolysis of mouse granulosa cells [8]. Thus, WT, $\triangle$ sseK3 mutant and sseK3-complemented strains were used to explore the ability of macrophage glycolysis through detecting the levels of pyruvic acid, lactic acid and ATP. We found that the levels of intracellular pyruvic acid did not significantly change among all groups from $2 \mathrm{~h}$ to $8 \mathrm{~h}(P>0.05)$, but the lactic acid and ATP were different, respectively, among these groups. In the beginning stage, compared with WT and sseK3-complemented groups, the level of lactic acid of microphages infected by $\Delta s s e K 3$ mutant strain did not significantly change at $2 \mathrm{~h}(P>0.05)$, while there was significant difference between WT and $\triangle$ sseK3 mutant group at $4 \mathrm{~h}(* * * P<0.001), 6 \mathrm{~h}(* * * P<0.001)$ and $8 \mathrm{~h}(* \star * P<0.001)$, suggesting the deletion of sseK3 may reduce the glycolysis of macrophages induced by $S$. Typhimurium and SseK3 encoded by sseK3 may enhance the glycolysis. Furthermore, the levels of lactic acid of WT, $\Delta s s e K 3$ mutant and sseK3-complemented strains were significantly larger than mock group from $2 \mathrm{~h}$ to $8 \mathrm{~h}$ ( $* * P<0.001)$, which illustrated that the anaerobic pathway of macrophages was enhanced among infection groups. Besides, as for ATP, there was no significant difference among all groups at $2 \mathrm{~h}$, while the ATP levels of macrophages of $\triangle s s e K 3$ mutant group were remarkably larger than that of WT and sseK3-complemented groups at $4 \mathrm{~h}(* \star * P<0.001), 6 \mathrm{~h}(* * P<0.01)$ and $8 \mathrm{~h}(* \star * P<0.001)$, indicating that glycolysis level of WT and sseK3-complemented groups were lower than $\Delta$ sseK3 mutant group and SseK3 encoded by sseK3 may enhance the glycolysis. Moreover, the ATP levels of macrophages of mock group were significantly higher than infections groups at $4 \mathrm{~h}(* \star * P<0.001), 6 \mathrm{~h}(* \star \star P<0.01)$ and $8 \mathrm{~h}$ $(* \star *<0.001)$, respectively, which suggested that the mock group may mainly undergoing the aerobic metabolism, for the prominent reason may be that the ATP produced by glycolysis is much lower than ATP produced by aerobic oxidation pathway. Therefore, the deletion of $s s e K 3$ decreased the glycolysis of $\Delta s s e K 3$ group compared with WT group and SseK3 could improve the level glycolysis of macrophages infected by $S$. Typhimurium. In a word, the SseK3 of $S$. Typhimurium could induce apoptosis and enhance the glycolysis of macrophages. The conclusion was consistent with Sumi's [44] and Ding's [35] results, but it was contradict with Li's [43] and Comin-Anduix's [40] results. We speculate that there may be other different pathways involved in the apoptosis and glycolysis of cells, which need more experiments to explain this problem. In our future work, we will further explore the relationship between glycolysis and apoptosis.

\section{Conclusions}

In summary, from what has been discussed above, we could conclude that the SseK3 of S. Typhimurium could induce cell apoptosis and boost glycolysis in macrophages. This finding may help to illustrate the mechanism that $\mathrm{S}$. Typhimurium induces macrophages apoptosis and provide a better understanding of the possible relationship between macrophage apoptosis and glycolysis induced by SseK3.

\section{Methods}

\section{Bacterial Strains, cells and culture}


S.Typhimurium SL1344, the deletion of sseK3 S.Typhimurium SL1344 ( $\Delta$ sseK3 mutant) and its complemented (sseK3-complemented) were used in this study. Macrophages RAW264.7 cells were obtained from the American Type Culture Collection (ATCC, Manassas, VA), and cells were cultured in Dulbecco's Modified Eagle Medium (DMEM)/high-glucose medium (HyClone, USA) containing 10\% fetal calf serum (FCS) in an incubator at $37{ }^{\circ} \mathrm{C}$ and $5 \% \mathrm{CO}_{2}$.

\section{Adherence and invasion assay}

Adhesion and invasion of RAW264.7 cells was assessed as previously described [48, 49]. A 24-well cell culture plate was inoculated with $1 \times 10^{5}$ RAW264.7 cells per well and incubated for $16 \mathrm{~h}$. WT, $\Delta s s e K 3$ mutant and sseK3-complemented strains were coincubated with RAW264.7 cells at a multiplicity of infection (MOI) of 100:1, with three replicate wells per strain. To allow the bacteria to fully contact the RAW264.7 cells, the plates were centrifuged and incubated with $5 \% \mathrm{CO}_{2}$ for $2 \mathrm{~h}$ at $37{ }^{\circ} \mathrm{C}$. For the adherence assay, the supernatants were aspirated, and the cells were washed three times with PBS. Subsequently, the cells were digested with $0.25 \%$ trypsin and plated in a gradient dilution and counted. For the invasion assay, the supernatants were aspirated, the cells were washed three times with PBS, and gentamicin-containing medium $(100 \mu \mathrm{g} / \mathrm{mL})$ was added and incubated at $37{ }^{\circ} \mathrm{C}$ with $5 \% \mathrm{CO}_{2}$. After incubation, the supernatants were aspirated, and the cells were washed three times with PBS. Subsequently, the cells were lysed using $0.1 \%$ Triton X-100 and plated with a gradient dilution and counted.

\section{Flow cytometry assay}

A 6-well cell culture plate was inoculated with $1 \times 10^{6}$ RAW264.7 cells per well and incubated for $16 \mathrm{~h}$. WT, $\Delta$ sseK3 mutant and sseK3-complemented strains were coincubated with RAW264.7 cells at a multiplicity of infection (MOI) of 100:1, with three replicate wells per strain. To allow the bacteria to fully contact the RAW264.7 cells, the plates were centrifuged with $1000 \mathrm{rpm} / \mathrm{min}$. After $4 \mathrm{~h}$, the percent of cells undergoing apoptosis was detected by flow cytometry using Annexin V-FITC/PI apoptosis detection kit (KeyGEN BioTECH Jiangsu China). The cells of infected and mock groups were digested with $0.25 \%$ trypsin and washed three times with ice-cold phosphate buffered saline (PBS) and suspended in Binding Buffer with $500 \mu \mathrm{L}$, followed by adding $5 \mu \mathrm{L}$ Annexin V-FITC and $5 \mu \mathrm{L}$ Propidium lodide (PI). Then the solution was placed in the dark room for $15 \mathrm{~min}$ at room temperature followed by immediately analysis using flow cytometry (Beckman Coulter, Inc., Fullerton, CA, US).

\section{Caspase-3, caspase-8 and caspase- 9 activity assay}

The activitiy of caspase-3, caspase-8, and caspase- 9 was measured by Caspase-3 Assay Kit, Caspase-8 Assay Kit, Caspase-9 Assay Kit (Beyotime, Shanghai, China), respectively. The cells of infected and mock groups were digested by trypsinization without EDTA and washed three times with ice-cold lysis buffer 3 times, followed by adding $100 \mu \mathrm{L}$ lysis buffer on ice. After incubated for 15 minutes, the concentration of 
protein was detected using the Bradford protein assay kit (Beyotime, Shanghai, China). Subsequently, after the cell lysates were incubated with Ac-DEVD-pNA for $4 \mathrm{~h}$ at $37^{\circ} \mathrm{C}$, the samples were read at $405 \mathrm{~nm}$.

\section{Glycolysis level assay}

The glycolysis levels were measured using pyruvic acid analysis kit, lactic acid analysis kit and ATP analysis kit respectively, which were purchased from Nanjing Jiancheng Bioengineering Institute (Nanjing, China). WT, $\triangle$ sseK3 mutant and sseK3-complemented groups were processed based on manufacturer's instruction at $2 \mathrm{~h}, 4 \mathrm{~h}, 6 \mathrm{~h}$ and $8 \mathrm{~h}$, respectively. The concentration of protein each group was detected using the Bradford protein assay kit (Beyotime, Shanghai, China). Finally, the absorbance values of pyruvic acid analysis kit, lactic acid analysis kit and ATP analysis kit were read at $505 \mathrm{~nm}, 530 \mathrm{~nm}$ and $636 \mathrm{~nm}$ in a microplate spectrophotometer, respectively.

\section{Statistical analysis}

The data are presented as the mean \pm standard deviation (SD) of three independent experiments, as based on triplicates assays. Two-way analysis of variance (ANOVA) with a post-hoc test (Bonferroni's multiple-comparison test) was used to compare and assess significance of the differences among all groups. The value of ${ }^{*} P<0.05, \star \star * P<0.01$ or ${ }^{\star \star \star} P<0.001$ was considered significant.

\section{Declarations}

\section{Ethics approval and consent to participate}

Not applicable.

\section{Acknowledgements}

We thank Roy Curtiss III (at the Department of Biology, Washington University, St. Louis, MO) for the generous donation of strains and plasmids.

\section{Funding}

This study was funded by grants from National Natural Science Foundation of China (31572489 and 31302059), the National Natural Science Foundation of Henan (182300410078), Henan Science and Technology Key Project (182102110061).

\section{Availability of data and materials}

The data generated and/or analyzed during the current study are available from the corresponding author on reasonable request.

\section{Consent for publication}

Not applicable. 
FD and CY performed the experiments, analyzed the experimental results and wrote manuscript. FD, CY, and $\mathrm{CZ}$ conceived of and designed the experiments. $\mathrm{FD}, \mathrm{CY}, \mathrm{CZ}$, and $\mathrm{YL}$ analyzed experiment performance. $C L, L H$, and $X C$ analyzed and interpreted all of the data. $Y L, C L, L H$, and $X Z$ performed the statistical analyse. $\mathrm{CY}, \mathrm{CZ}, \mathrm{YL}$, and $\mathrm{XC}$ did the supervised study. All authors read and approved the manuscript.

\section{Competing interests}

The authors declare that they have no competing of interests.

\section{References}

1. Zhang X, He L, Zhang C, Yu C, Yang Y, Jia Y, Cheng X, Li Y, Liao C, Li J et al: The impact of sseK2 deletion on Salmonella enterica serovar typhimurium virulence in vivo and in vitro. BMC Microbiol 2019, 19(1):182.

2. Kalaba V, Golić B, Ž Sladojević, Kalaba D: Incidence of Salmonella Infantis in poultry meat and products and the resistance of isolates to antimicrobials. IOP Conference Series: Earth and Environmental Science 2017, 85:012082.

3. Vazquez-Torres A, Jones-Carson J, Bäumler AJ, Falkow S, Valdivia R, Brown W, L M, Berggren R, Parks W T, Fang F C: Extraintestinal dissemination of Salmonella by CD18-expressing phagocytes. Nature 1999, 401(6755):804-808.

4. Planqué R, Bruggeman FJ, Teusink B, Hulshof $\mathrm{J}$ : Understanding bistability in yeast glycolysis using general properties of metabolic pathways. Math Biosci 2014, 255(1):33-42.

5. Phypers B, Pierce JT: Lactate physiology in health and disease. Contin Educ Anaesth Crit Care Pa 2006, 6(3):128-132.

6. Liu Y, Tong L, Luo Y, Li X, Chen G, Wang Y: Resveratrol inhibits the proliferation and induces the apoptosis in ovarian cancer cells via inhibiting glycolysis and targeting AMPK/mTOR signaling pathway. J Cell Biochem 2018, 119(7):6162-6172.

7. Kok SH, Hou KL, Hong CY, Chao LH, Hsiang-Hua Lai E, Wang HW, Yang H, Shun CT, Wang JS, Lin SK: Sirtuin 6 Modulates Hypoxia-induced Apoptosis in Osteoblasts via Inhibition of Glycolysis: Implication for Pathogenesis of Periapical Lesions. J Endodont 2015, 41(10):1631-1637.

8. Zhou J, Li C, Yao W, Alsiddig MC, Huo L, Liu H, Miao YL: Hypoxia-inducible factor-1a-dependent autophagy plays a role in glycolysis switch in mouse granulosa cells. Biol Reprod 2018, 99(2):308318.

9. Wijburg OLC, Nico VR, Strugnell RA: Induction of CD8+ T lymphocytes by Salmonella typhimurium is independent of Salmonella pathogenicity island 1-mediated host cell death. J Immunol 2002, 169(6):3275-3283. 
10. Kasinskas RW, Forbes NS: Salmonella typhimurium lacking ribose chemoreceptors localize in tumor quiescence and induce apoptosis. Cancer Res 2007, 67(7):3201-3209.

11. Shi-Wei H, Jun-Kai K, Chun-Ying W, Sin-Ting W, Hsin-Chen L, Shu-Mei L, Yi-Ju C, Jeng-Jer S: Targeting aerobic glycolysis and HIF-1alpha expression enhance imiquimod-induced apoptosis in cancer cells. Oncotarget 2014, 5(5):1363-1381.

12. Kok SH, Hou KL, Hong CY, Chao LH, Lai HH, Wang HW, Yang H, Shun CT, Wang JS, Lin SK: Sirtuin 6 Modulates Hypoxia-induced Apoptosis inOsteoblasts via Inhibition of Glycolysis: ImplicationforPathogenesis of Periapical Lesions. J Endodont 2015, 41(10):1631-1637.

13. Liu X, Zhao H, Jin Q, You W, Cheng H, Liu Y, Song E, Liu G, Tan X, Zhang X: Resveratrol induces apoptosis and inhibits adipogenesis by stimulating the SIRT1-AMPKa-FOXO1 signalling pathway in bovine intramuscular adipocytes. Mol Cell Biochem 2018, 439(1-2):213-223.

14. Sanman LE, Qian Y, Eisele NA, Ng TM, Wa VDL, Monack DM, Weerapana E, Bogyo M: Disruption of glycolytic flux is a signal for inflammasome signaling and pyroptotic cell death. Elife 2016, 5:e13663.

15. Bowden SD, Gary R, Hinton JCD, Arthur T: Glucose and glycolysis are required for the successful infection of macrophages and mice by Salmonella enterica serovar typhimurium. Infect Immun 2009, 77(7):3117-3126.

16. Jennings E, TIm T, Holden DW: Salmonella SPI-2 Type III Secretion System Effectors: Molecular Mechanisms And Physiological Consequences. Cell Host Microbe 2017, 22(2):217-231.

17. Ochman H, Soncini F C, Solomon F, Groisman E A: Identification of a pathogenicity island required for Salmonella survival in host cells. Proc Natl Acad Sci U S A 1996, 93(15):7800-7804.

18. Hensel M, Shea JE, Gleeson C, Jones MD, Dalton E, Holden DW: Simultaneous identification of bacterial virulence genes by negative selection. Science 1995, 269(5222):400-403.

19. Yang Z, Soderholm A, Lung TWF, Giogha C, Hill MM, Brown NF, Hartland E, Teasdale RD: SseK3 Is a Salmonella Effector That Binds TRIM32 and Modulates the Host's NF-KB Signalling Activity. PLOS One 2015, 10(9):e0138529.

20. Esposito D, Günster RA, Martino L, El KO, Wagner A, Thurston T, Rittinger K: Structural basis for the glycosyltransferase activity of the Salmonella effector SseK3. J Biol Chem 2018, 293(14):5064-5078.

21. Brown NF, Coombes BK, Bishop JL, Wickham ME, Lowden MJ, Gal-Mor O, Goode DL, Boyle EC, Sanderson KL, Finlay BB: Salmonella Phage ST64B Encodes a Member of the SseK/NleB Effector Family. PLoS One 2011, 6(3):e17824.

22. Zhang $\mathrm{H}$, Yong $\mathrm{H}$, Qian $\mathrm{D}$, Luo $\mathrm{X}$, Liang Z, Zhao X, Tong D: Porcine parvovirus infection induces apoptosis in PK-15 cells through activation of p53 and mitochondria-mediated pathway. Biochem Bioph Res Co 2015, 456(2):649-655.

23. He J, Wang C, Sun Y, Lu B, Cui J, Dong N, Zhang M, Liu Y, Yu B: Exendin-4 protects bone marrowderived mesenchymal stem cells against oxygen/glucose and serum deprivation-induced apoptosis through the activation of the CAMP/PKA signaling pathway and the attenuation of ER stress. Int $J$ Mol Med 2016, 37(4):889-900. 
24. Ding L, Huang Y, Du Q, Dong F, Zhao X, Zhang W, Xu X, Tong D: TGEV nucleocapsid protein induces cell cycle arrest and apoptosis through activation of p53 signaling. Biochem Bioph Res Co 2014, 445(2):497-503.

25. Wang G, Xu Z, Wang C, Yao F, Li J, Chen C, Sun S: Differential phosphofructokinase-1 isoenzyme patterns associated with glycolytic efficiency in human breast cancer and paracancer tissues. Oncol Lett 2013, 6(6):1701-1706.

26. Chen D, Liao Y, Xu Q, Li Y, Wu W, Wu J, Liao W, Xu D, Liu Y, Wu P: Persistence of systolic and diastolic regional dysfunction after brief episodes of myocardial ischemia evaluated with velocity vector imaging. Int j Cardiol 2013, 167(3):987-994.

27. Jia Y, Cong R, Li R, Yang X, Sun Q, Parvizi N, Zhao R: Maternal low-protein diet induces genderdependent changes in epigenetic regulation of the glucose-6-phosphatase gene in newborn piglet liver. J Nutr 2012, 142(9):1659-1665.

28. Ibarra JA, Steele-Mortimer O: Salmonella â咽 the ultimate insider. Salmonella virulence factors that modulate intracellular survival. Cell Microbiol 2010, 11(11):1579-1586.

29. Günster RA, Matthews SA, Holden DW, Thurston TL: SseK1 and SseK3 T3SS effectors inhibit NF-kB signalling and necroptotic cell death in Salmonella-infected macrophages. Infect Immun 2017, 85(3):e00010-00017.

30. Kujat Choy SL, Boyle EC, Gal-Mor O, Goode DL, Valdez Y, Vallance BA, Finlay BB: SseK1 and SseK2 are novel translocated proteins of Salmonella enterica serovar Typhimurium. Infect Immun 2004, 72(9):5115-5125.

31. Mcintosh A, Meikle LM, Ormsby MJ, Mccormick BA, Christie JM, Brewer JM, Roberts M, Wall DM: SipA Activation of Caspase-3 Is a Decisive Mediator of Host Cell Survival at Early Stages of Salmonella enterica Serovar Typhimurium Infection. Infect Immun 2017, 85(9):IAl.00393-00317.

32. He P, Wu S, Chu Y, Yang Y, Li Y, Huang R: Salmonella enterica serovar Typhi plasmid pR ST98 enhances intracellular bacterial growth and S. typhi -induced macrophage cell death by suppressing autophagy. Braz J Infect Dis 2012, 16(3):262-266.

33. Santos RL, Tsolis RM, Bäumler AJ, Smith R, Adams LG: Salmonella enterica serovar typhimurium induces cell death in bovine monocyte-derived macrophages by early sipB-dependent and delayed sipB-independent mechanisms. Infect Immun 2001, 69(4):2293-2301.

34. RW K, NS F: Salmonella typhimurium lacking ribose chemoreceptors localize in tumor quiescence and induce apoptosis. Cancer Res 2007, 67(7):3201-3209.

35. Ding K, Zhang C, Li J, Chen S, Liao C, Cheng X, Yu C, Yu Z, Jia Y: cAMP Receptor Protein of Salmonella enterica Serovar Typhimurium Modulate Glycolysis in Macrophages to Induce Cell Apoptosis. Curr Microbiol 2019, 76(1):1-6.

36. Wei Y, Kong B, Song K, Qu X, Jin Q, Yang Q: Involvement of mitochondria-caspase pathway in Hemoporfin-mediated cell death. Photochem Photobiol 2010, 83(6):1319-1324.

37. Knodler LA, B Brett F, Olivia SM: The Salmonella effector protein SopB protects epithelial cells from apoptosis by sustained activation of Akt. J Biol Chem 2005, 280(10):9058-9064. 
38. Hans HC, Christine F, Hermann W, Georg HC: Caspase-9/-3 activation and apoptosis are induced in mouse macrophages upon ingestion and digestion of Escherichia coli bacteria. J Immunol 2002, 169(6):3172-3179.

39. Ming MS, Panagiotis T, Lee H, Monie TP, Fitzgerald KA, Bryant CE: Salmonella infection induces recruitment of Caspase-8 to the inflammasome to modulate IL-1 $\beta$ production. J Immuno/ 2013 , 191(10):5239-5246.

40. Comin-Anduix B, Boros LG, Marin S, Boren J, Callol-Massot C, Centelles JJ, Torres JL, Agell N, Bassilian S, Cascante M: Fermented wheat germ extract inhibits glycolysis/pentose cycle enzymes and induces apoptosis through poly(ADP-ribose) polymerase activation in Jurkat T-cell leukemia tumor cells. J Biol Chem 2002, 277(48):46408-46414.

41. Jeong DW, Kim TS, Cho IT, Kim IY: Modification of glycolysis affects cell sensitivity to apoptosis induced by oxidative stress and mediated by mitochondria. Biochem Bioph Res Co 2004, 313(4):984991.

42. Zhu Y, Ramos da Silva S, He M, Liang Q, Lu C, Feng P, Jung JU, Gao SJ: An Oncogenic Virus Promotes Cell Survival and Cellular Transformation by Suppressing Glycolysis. PLoS Pathog 2016, 12(5):e1005648.

43. Li J, Chen K, Wang F, Dai W, Li S, Feng J, Wu L, Liu T, Xu S, Xia Y: Methyl jasmonate leads to necrosis and apoptosis in hepatocellular carcinoma cells via inhibition of glycolysis and represses tumor growth in mice. Oncotarget 2017, 8(28):45965-45980.

44. Sumi C, Okamoto A, Tanaka H, Nishi K, Kusunoki M, Shoji T, Uba T, Matsuo Y, Adachi T, Hayashi Jl: Propofol induces a metabolic switch to glycolysis and cell death in a mitochondrial electron transport chain-dependent manner. PLoS One 2018, 13(2):e0192796.

45. Merlin TY, Leatham MP, Allen JH, Laux DC, Tyrrell C, Cohen PS: Role of gluconeogenesis and the tricarboxylic acid cycle in the virulence of Salmonella enterica serovar Typhimurium in BALB/c mice. Infect Immun 2006, 74(2):1130-1140.

46. Lecarpentier Y, Claes V, Vallée A, Hébert JL: Thermodynamics in cancers: opposing interactions between PPAR gamma and the canonical WNT/beta-catenin pathway. Clin Trans/Med, 2017, 6(14):1-11.

47. Mickelson MN: Glucose Degradation, MolarGrowthYields, and Evidence forOxidative Phosphorylation in Streptococcus agalactiae. J Bacterio/ 1972, 109(1):96-105.

48. Shippy DC, Eakley NM, Bochsler PN, Fadl AA: Biological and virulence characteristics of Salmonella enterica serovar Typhimurium following deletion of glucose-inhibited division ( gidA) gene. Microb Pathog 2011, 50(6):303-313.

49. Yang Y, Yu C, Ding K, Zhang C, Liao C, Jia Y, Li J, Cheng X: Role of the sseK1 gene in the pathogenicity of Salmonella enterica serovar enteritidis in vitro and in vivo. Microb Pathog 2018, 117(117): 270-275.

\section{Figures}




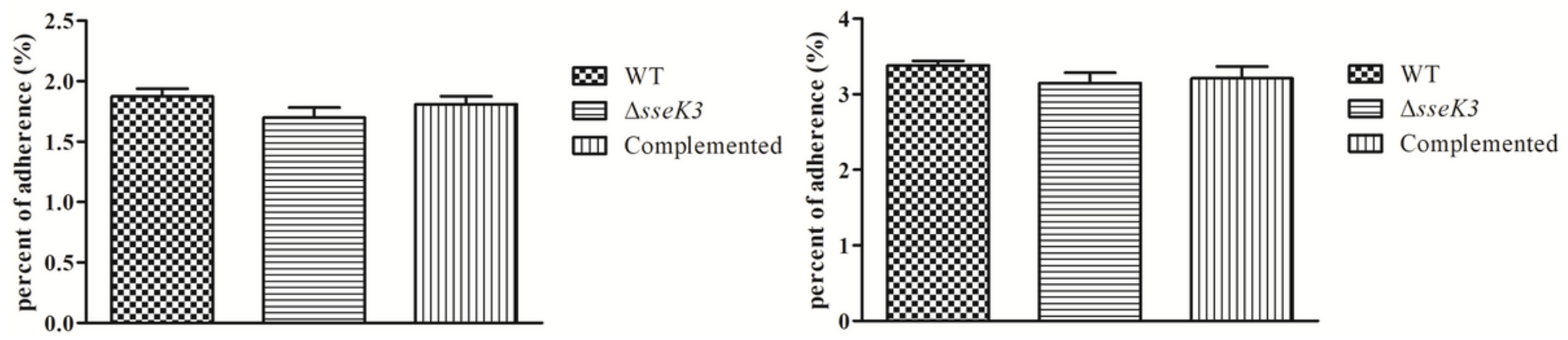

\section{Figure 1}

Adherence and invasion assays for WT, $\Delta$ sseK3 mutant and sseK3-complemented strains to RAW264.7 cells. There were no significant differences using Bonferroni's multiple-comparison test among all groups $(P>0.05)$.

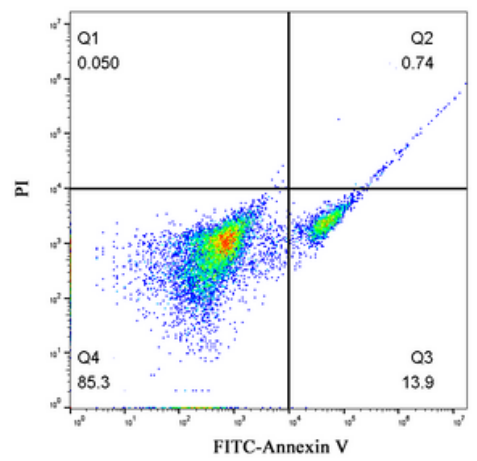

WT

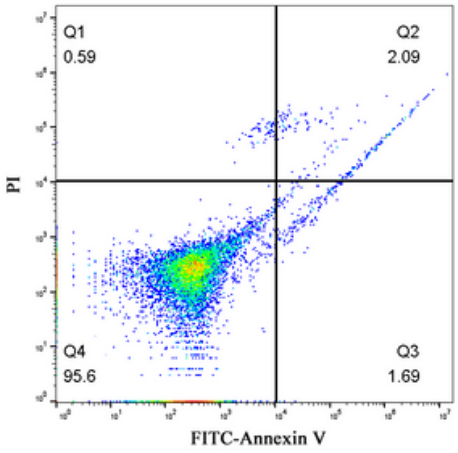

$\Delta s s e K 3$

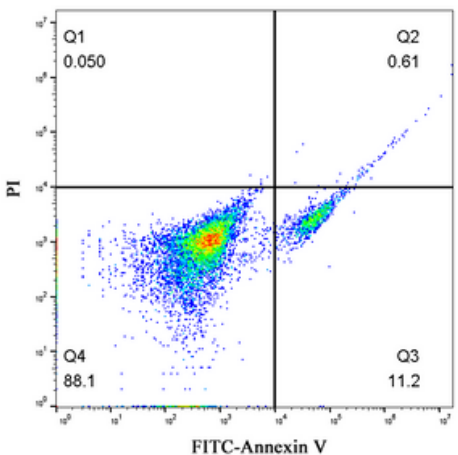

Complemented

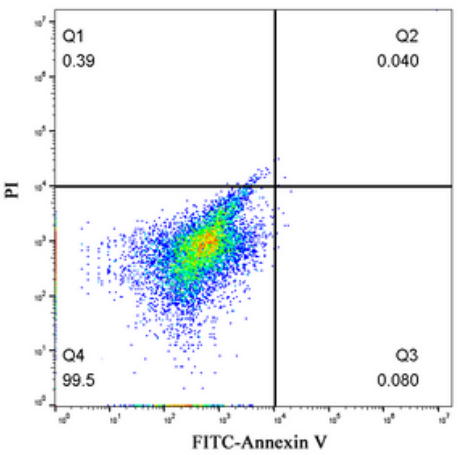

Mock

Figure 2

The apoptosis percent of RAW264.1 cells infected by WT, $\Delta$ sseK3 mutant and its complemented strains. Apoptosis was assessed by using Annexin V-FITC/PI double staining. 

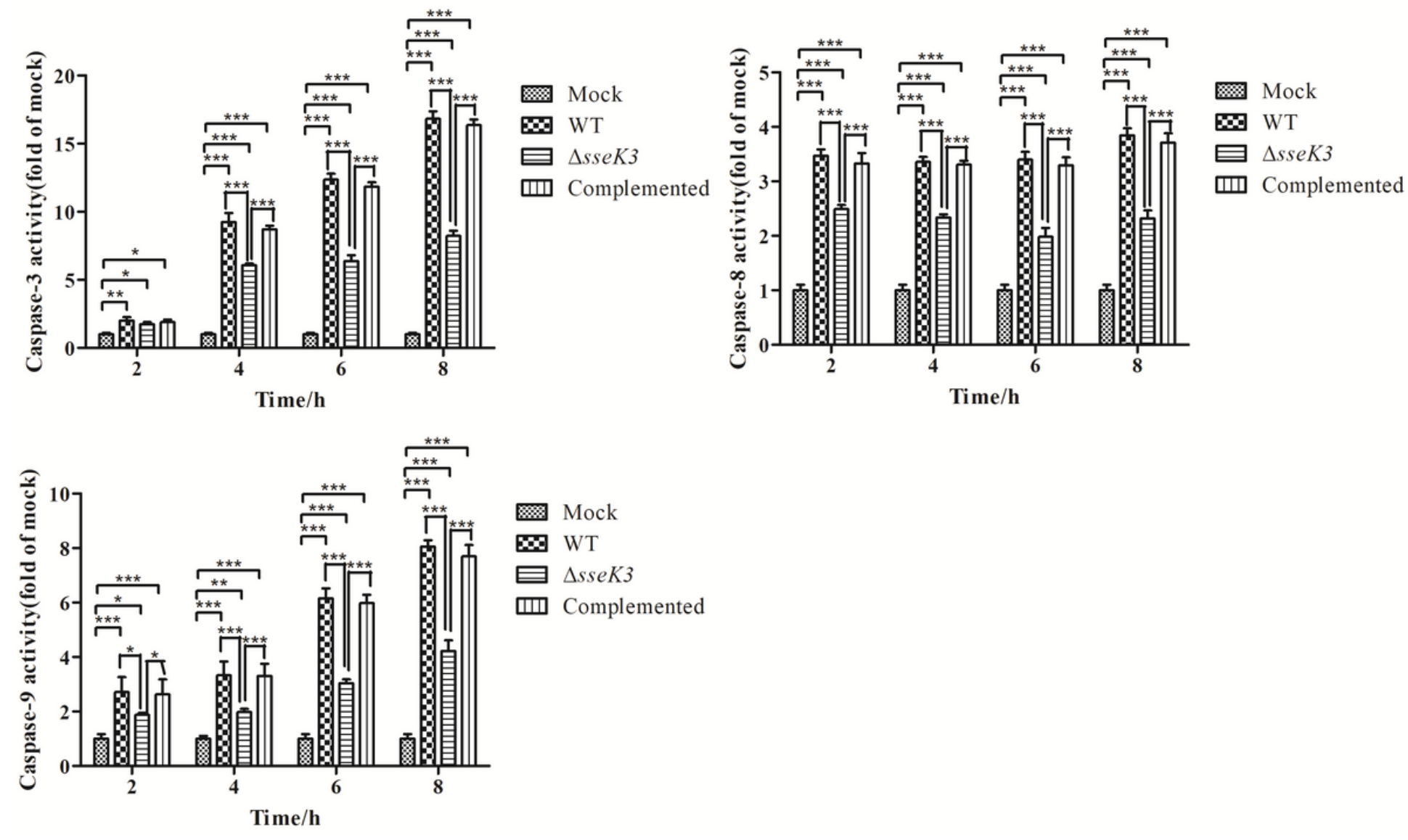

Figure 3

The activity of caspase-3, caspase- 8 and caspase-9 in RAW264.7 cells of all groups. The activity of caspase- $3,-8$, and -9 was measured by colorimetric assay and analyzed using two-way ANOVA with Bonferroni's multiple-comparison test $\left({ }^{*} P<0.05,{ }^{* *} P<0.01,{ }^{\star * *} P<0.001\right)$. Results are means \pm SD. 

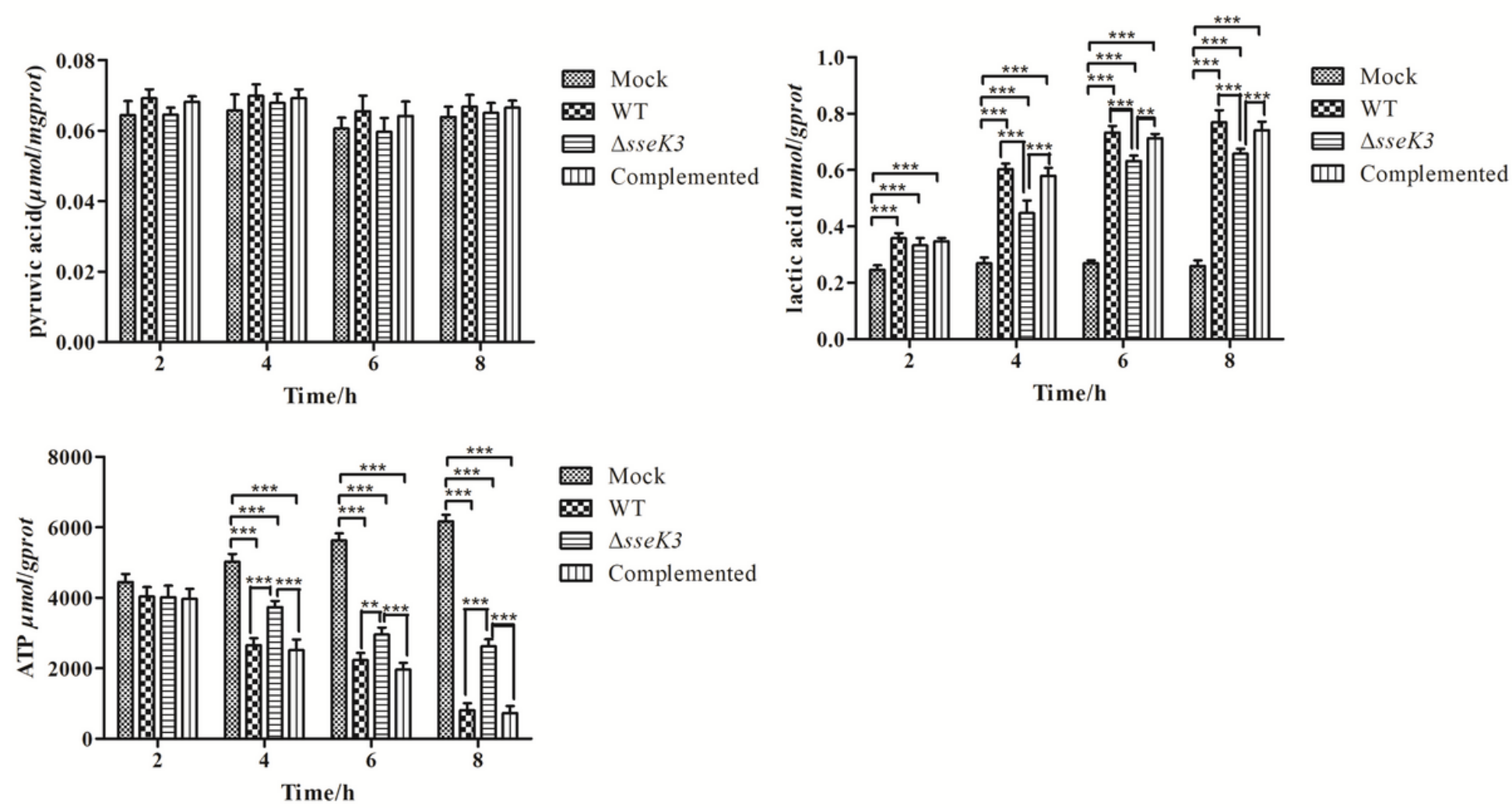

Figure 4

The glycolysis of RAW264.7 infected by WT, $\Delta$ sseK3 mutant and sseK3-complemented strains. The content of pyruvic acid, lactic acid and ATP were measured by colorimetric assay and analyzed using two-way ANOVA with Bonferroni's multiple-comparison test ( ${ }^{\star} P<0.05$, $\left.{ }^{\star \star P} P<0.01,{ }^{\star \star \star} P<0.001\right)$. Results are means \pm SD. 